\title{
A Triangle: COVID-19, Breast Cancer, and Cancer Therapy
}

\author{
AmirAli Moodi Ghalibaf $\mathbb{( i}^{1, *}$ \\ ${ }^{1}$ Student Research Committee, Faculty of Medicine, Mashhad University of Medical Sciences, Mashhad, Iran \\ "Corresponding author: Student Research Committee, Faculty of Medicine, Mashhad University of Medical Sciences, Mashhad, Iran. Email: amiralimoodi1998@gmail.com \\ Received 2021 April 24; Revised 2021 May 15; Accepted 2021 May 15.
}

Keywords: COVID-19, Breast Cancer, Cancer Therapy

\section{Dear editor,}

Since the initiation of the novel coronavirus disease 2019 (COVID-19) crisis at the end of 2019, the world got shocked in the face of this mysterious virus (1). Because of the COVID-19's ambiguous pathogenesis mechanisms and impact on the human cell lines, there are no approved pharmaceutical treatment and/or preventive measures for the disease yet, and unfortunately, COVID-19 has caused more than 2 million deaths all over the world up to now (2, 3 ). In the meantime, cancer patients seem to be more vulnerable to the complications of COVID-19 due to their specific conditions; however, it cannot be surely said that this virus is not oncogenic. As breast cancer is one of the most prevalent malignancies among women all over the world, we investigated the possible effects of COVID-19 on breast cell lines and the breast cancer patient's condition during this phenomenon.

Can COVID-19 infection increase the risk of cancer incidence, especially breast cancer?

There is no strong evidence about the oncogenic behavior of the COVID-19 infection like other viral infections associated with certain malignancies, such as Epstein-Barr virus (EBV), human immunodeficiency virus (HIV), human papillomavirus (HPV), hepatitis B virus (HBV), and hepatitis $C$ virus (HCV), but COVID-19 can be potentially considered suspicious as an oncolytic virus. In detail, binding the spike proteins of this coronavirus with angiotensin converting enzym 2 (ACE2) can lead to the entrance of the virus into the cell and its replication, while several studies have determined that the overexpression of ACE2 has protective effects in breast cancer by suppressing angiogenesis and cell growth $(4,5)$. On the other hand, the long-time severe cytokine storm over the COVID-19 infection can potentially have an unsuitable impact on breast cell lines and increase the risk of malignancy (6). Also, according to Francescangeli et al. (7), COVID-19 can affect dormant cancer cells
(DDCs) and cause their reactivation. Previous studies have indicated that patients with a history of cancer can harbor DDCs; therefore, the conditions following COVID-19's infection, including inflammation and neutrophil extracellular traps (NETs), can lead to the old cancer flare-up or relapse. Besides, it is essential to mention the role of psychological distress, such as stress, anxiety, depression, etc., in cancer occurrence and outcomes (8); while, the current COVID-19 disaster has weakened people's mental health (Figure 1).

What are the impacts of COVID-19 infection on breast cancer patients?

According to the particular situation of cancer patients, especially breast cancer patients, they are more at risk of being infected by COVID-19; moreover, there is a higher risk of severer outcomes of the infection in the cancerous population. It seems that the main cause of this phenomenon could be due to the immunosuppressed status of cancer patients because their immune system cannot defend the body as properly as the non-cancer patients. Meanwhile, Bidard et al. indicated that the outcomes of COVID-19 in breast cancer patients depend on their comorbidities and are less associated with cancer therapies, by which their immune system may be suppressed strongly. However, some other studies have determined that the outcomes and severity of other types of neoplasms, including solid tumors and hematological malignancies are significantly associated with cancer therapies (Figure 1) $(9,10)$.

Finally, it can be stated that all people need to protect their selves against COVID-19; first, because of its effects on people's quality of life, the direct complications of the infections, and its mortality; second, because of the unknown impact of this novel virus on human cell lines, such as the possible oncogenic effects of the novel coronavirus. Furthermore, during this pandemic, cancer patients need more protection against getting infected than other people because less is known about the certain effects of the COVID-19 on cancer patients, especially breast cancer pa- 


\section{A triangle: COVID-19, Breast Cancer, and Cancer therapy}

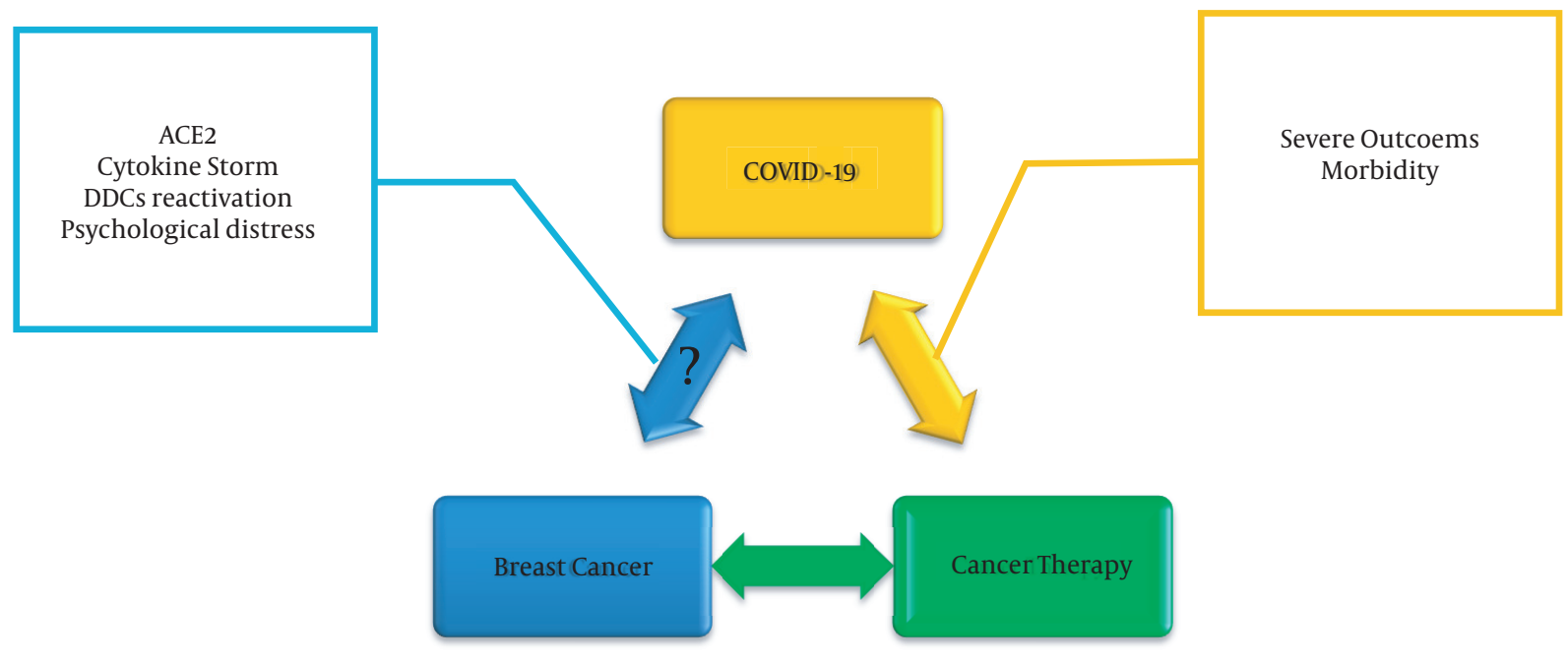

Figure 1. The schematic of the possible relationship between COVID-19, breast cancer, and cancer therapy

tients. Therefore, prevention is the best way to protect ourselves and others against the mysterious COVID-19. Obviously, further studies and investigations are required to find the gray areas of this virus's behaviors.

\section{Footnotes}

Authors' Contribution: Amir Ali Moodi Ghalibaf wrote the main manuscript as the first and corresponding author.

Conflict of Interests: The author declares that there was no conflict of interests.

Funding/Support: This study was conducted without any financial support and funding.

\section{References}

1. Wu F, Zhao S, Yu B, Chen YM, Wang W, Song ZG, et al. A new coronavirus associated with human respiratory disease in China. $\mathrm{Na}$ ture. 2020;579(7798):265-9. doi: 10.1038/s41586-020-2008-3. [PubMed: 32015508]. [PubMed Central: PMC7094943].

2. Stahlmann R, Lode H. Medication for COVID-19-an Overview of Approaches Currently Under Study. Dtsch Arztebl Int. 2020;117(13):213-9. doi: 10.3238/arztebl.2020.0213. [PubMed: 32343658]. [PubMed Central: PMC7196844].

3. World Health Organization. COVID-19 weekly epidemiologica. 2021.
4. Wan Y, Shang J, Graham R, Baric RS, Li F. Receptor Recognition by the Novel Coronavirus from Wuhan: an Analysis Based on DecadeLong Structural Studies of SARS Coronavirus. J Virol. 2020;94(7). doi: 10.1128/JVI.00127-20. [PubMed: 31996437]. [PubMed Central: PMC7081895].

5. Zhang Q, Lu S, Li T, Yu L, Zhang Y, Zeng H, et al. ACE2 inhibits breast cancer angiogenesis via suppressing the VEGFa/VEGFR2/ERK pathway. J Exp Clin Cancer Res. 2019;38(1):173. doi: 10.1186/s13046-019-1156-5. [PubMed: 31023337]. [PubMed Central: PMC6482513].

6. Kozlowski L, Zakrzewska I, Tokajuk P, Wojtukiewicz MZ. Concentration of interleukin-6 (IL-6), interleukin-8 (IL-8) and interleukin-10 (IL10) in blood serum of breast cancer patients. Roczniki Akademii Medycznej w Bialymstoku (1995). 2003;48:82-4.

7. Francescangeli F, De Angelis ML, Zeuner A. COVID-19: a potential driver of immune-mediated breast cancer recurrence? Breast Cancer Res. 2020;22(1):117. doi: 10.1186/s13058-020-01360-0. [PubMed: 33126915]. [PubMed Central: PMC7598231].

8. Wang YH, Li JQ, Shi JF, Que JY, Liu JJ, Lappin JM, et al. Depression and anxiety in relation to cancer incidence and mortality: a systematic review and meta-analysis of cohort studies. Mol Psychiatry. 2020;25(7):1487-99. doi: 10.1038/s41380-019-0595-x. [PubMed: 31745237].

9. Vuagnat P, Frelaut M, Ramtohul T, Basse C, Diakite S, Noret A, et al. COVID-19 in breast cancer patients: a cohort at the Institut Curie hospitals in the Paris area. Breast Cancer Res. 2020;22(1):55. doi: 10.1186/s13058-020-01293-8. [PubMed: 32460829]. [PubMed Central: PMC7254663].

10. Yang K, Sheng Y, Huang C, Jin Y, Xiong N, Jiang K, et al. Clinical characteristics, outcomes, and risk factors for mortality in patients with cancer and COVID-19 in Hubei, China: a multicentre, retrospective, cohort study. Lancet Oncol. 2020;21(7):904-13. doi: 10.1016/s14702045(20)30310-7. 